Brit. Heart J., 1965, 27, 911.

\title{
SYPHILITIC OBSTRUCTION OF CORONARY OSTIA SUCCESSFULLY TREATED BY ENDARTERECTOMY
}

\author{
BY
}

\author{
W. BECK, C. N. BARNARD, AND V. SCHRIRE
}

From the Cardiac Clinic, Groote Schuur Hospital, the Council for Scientific and Industrial Research Cardiovascular-Pulmonary Research Group, the Departments of Medicine and Surgery, University of Cape Town, Cape Town, South Africa

Received December 7, 1964

Occlusion or narrowing of the coronary ostia by syphilitic aortitis is a rare disease. In 1950 Scharfman, Wallach, and Angrist, reviewing several large necropsy series, reported 935 cases of syphilitic aortitis in 33,176 necropsies. Of these, 24 had involvement of the coronary ostia. Effective treatment by endarterectomy has been reported by Blondeau and Dubost (1962), Michaud et al. (1963), and Connolly et al. (1964). In recent years we have encountered and successfully treated two such patients, in one of whom we were able to demonstrate the occlusion and successful postoperative result by cine-angiography.

\section{CASE REPORTS}

Case 1. A coloured man, aged 27, presented in 1961 with a 2-year history of classical angina pectoris occurring on effort and at rest. He had previously had a standard course of penicillin therapy for a positive

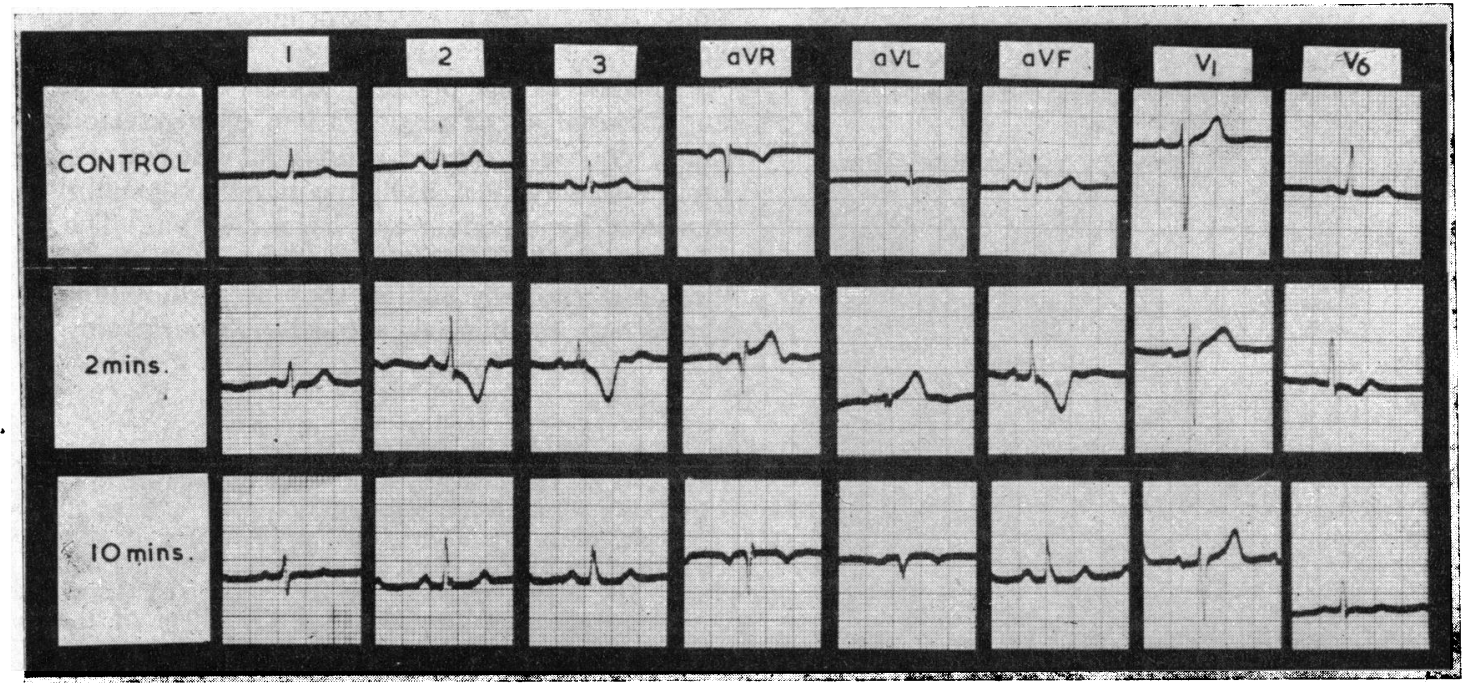

FIG. 1.-The electrocadiogram of Case 1 at rest is within normal limits, but conspicuous ischæmic S-T segment changes develop immediately after effort. 
Wassermann reaction without benefit. His symptom gradually increased in severity until he was unable to work or to walk more than $\mathbf{3 0}$ yards. He was completely incapacitated in spite of using up to 30 nitroglycerin tablets per day.

A

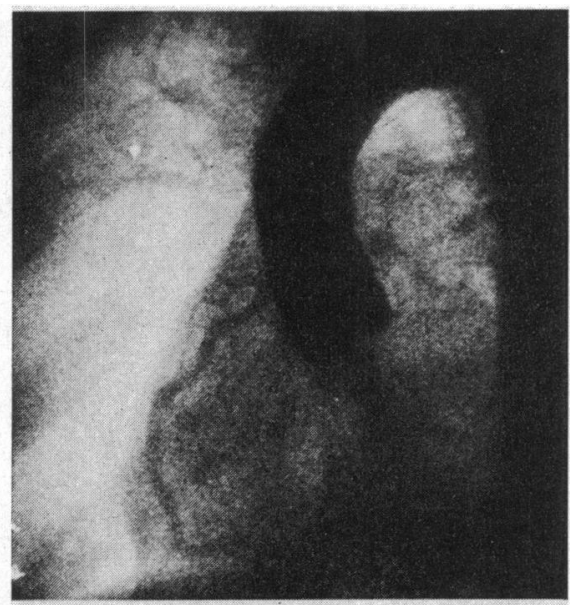

B

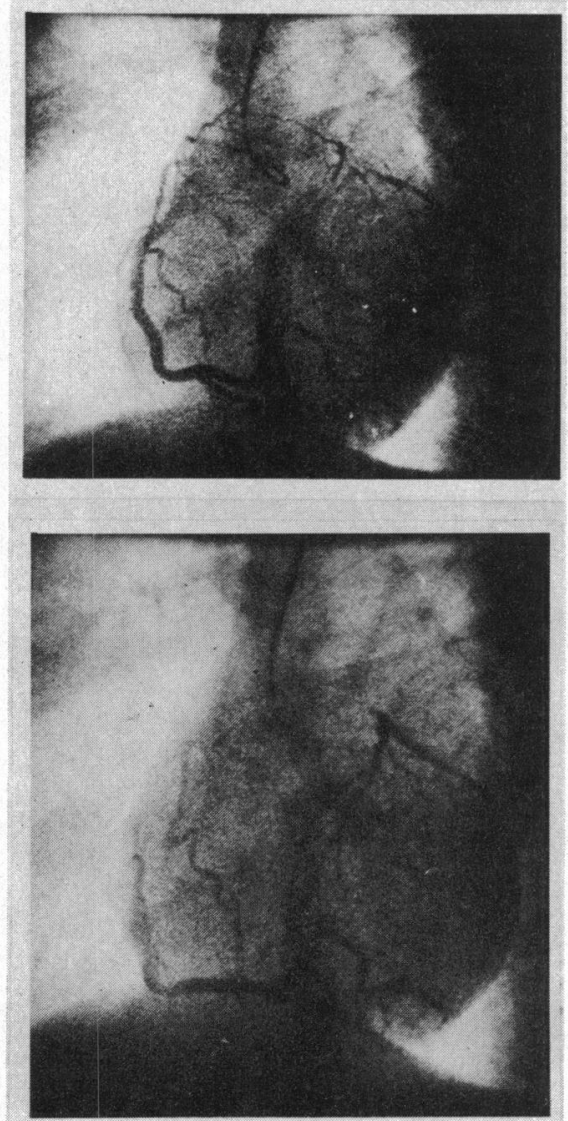

On examination he was normally developed with a normal pulse and a blood pressure of $130 / 80 \mathrm{~mm} . \mathrm{Hg}$. The heart was not enlarged. A very soft early diastolic murmur along the left sternal border suggested slight aortic regurgitation. The chest radiograph showed normal cardiac and aortic outlines, and the resting electrocardiogram was within normal limits. An effort test showed ischæmic S-T segment depression (Fig. 1). The clinical diagnosis was syphilitic aortitis with coronary ostial involvement and slight incompetence of the aortic valve.

A second course of penicillin therapy was instituted without significant improvement and in 1963 it was decided to study the state of the coronary arteries and aortic valve by means of aortic angiography with a view to corrective surgery. This demonstrated a mild degree of aortic incompetence and good filling of the right coronary artery. The left coronary was barely visible and filled late through collateral channels from the right coronary (Fig. 2A). Selective coronary cineangiography using the Sones technique showed a large dilated right coronary artery, with dilated atrial collateral branches supplying the left coronary artery near its bifurcation into anterior descending and circumflex branches (Fig. 2B and 2C). The flow through the collateral channels to the left coronary appeared to be inadequate as judged by the small vessel calibre, late filling, and slow clearance of the opaque medium. The left coronary ostium could not be probed despite repeated attempts. There was no evidence of obstruction at any site other than the origin of the left coronary artery.

In view of the patient's severe disability, youth, and minimal aortic regurgitation, endarterectomy of the left coronary ostium was advised. He was operated on in February 1964, using the pump oxygenator with moderate hypothermia and hæmodilution. The root of the ascending aorta was approached through a median sternotomy and, as soon as cardiopulmonary bypass was established, a transverse aortotomy was

Fig. 2.-(A) The pre-operative aortic angiogram in Case 1 shows some aortic regurgitation with a large dilated right coronary artery but no evidence of the left coronary arising from the aorta directly.

(B) A single frame from the selective right coronary cine-angiogram demonstrating the filling of the left coronary artery via atrial collateral channels.

(C) A later frame from the same angiogram demonstrating an apparently normal left coronary artery distal to the complete ostial obstruction. 


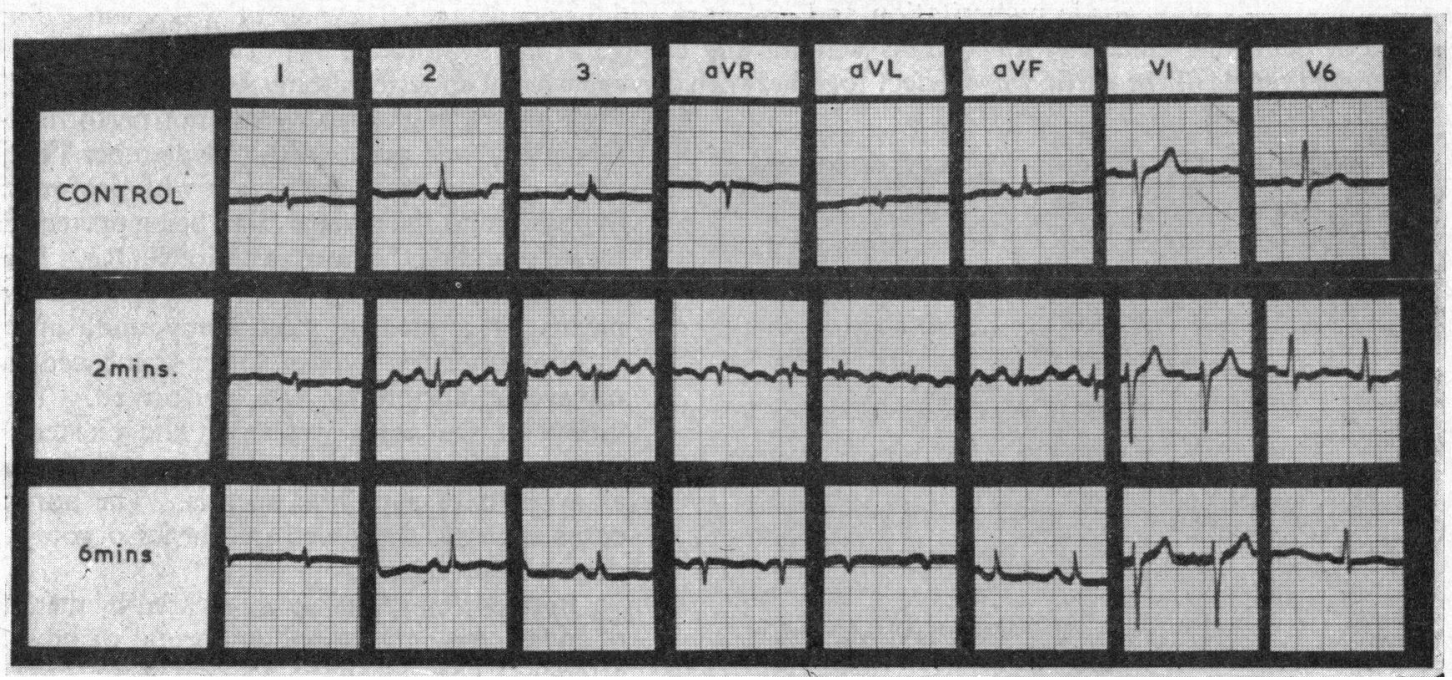

Fig. 3.-The electrocardiogram of Case 1 five months after operation shows slight non-specific $T$ wave flattening at rest. After effort junctional changes occur but no ischæmic pattern develops.

performed revealing complete occlusion of the left coronary ostium due to intimal proliferation. There was also slight narrowing of the right coronary ostium. The right coronary artery was cannulated and perfused with cold, oxygenated blood throughout the procedure.

As the left coronary ostium could not be seen, endarterectomy was commenced at the edge of the aortotomy and extended down towards the usual site of the left coronary ostium. As soon as the ostium was entered, there was a retrograde flow of bright red blood. This area was then widely cleared by endarterectomy. To prevent dissection, the intima of the coronary artery was sewn back into the ostium with a continuous 6-0 silk suture, as was the distal edge of the aortic intima, where the endarterectomy had been commenced. The aortotomy was closed with interrupted and continuous 4-0 silk sutures and the aortic clamp removed. After re-warming, the heart was defibrillated, bypass was discontinued at $34^{\circ} \mathrm{C}$., and the heart took over with a good beat.

The post-operative course was uneventful, the patient being discharged 3 weeks after operation completely free of pain. The post-operative electrocardiogram showed $T$ wave inversion of post-operative pericarditis at rest, but no ischæmic changes developed on severe effort. Subsequent follow-up has been equally satisfactory with complete relief of all symptoms.

Five months later the electrocardiogram was normal at rest and on effort (Fig. 3). Selective coronary and aortic cine-angiography now showed normal filling of both right and left coronary arteries with complete involution of the collateral channels (Fig. 4). The degree of aortic regurgitation remained unchanged.

Case 2. A white woman, aged 60, presented in 1962 with angina pectoris of 6 months' duration, of progressive.severity culminating in pain at rest. Her pain was always promptly relieved by nitroglycerin. She was only slightly dyspnœic on effort and had no other symptoms of cardiac decompensation.

On examination she was healthy looking but had a collapsing pulse and Corrigan sign in the neck. The blood pressure was $220 / 40 \mathrm{~mm}$.Hg. A slight thrill was palpable over the carotid artery. The cardiac apex was not displaced but the apical thrust suggested an overfilled left ventricle. On auscultation she had a short ejection systolic murmur (2/6) heard all over the front of the chest but maximal to the right of the sternum and conducted to the neck. Along the left sternal border there was a long early diastolic murmur of aortic regurgitation. At the apex a rumbling mid-diastolic murmur interpreted as an Austin Flint murmur was present. Radiography showed minimal cardiac enlargement with a conspicuously dilated aorta. The electrocardiogram showed the features of left ventricular hypertrophy.

The initial clinical impression was that of rheumatic aortic valve disease with dominant aortic regurgitation, but the disproportionate degree of cardiac ischæmia raised the question of superimposed coronary atheroma. Serological tests for syphilis, however, proved strongly positive, suggesting the diagnosis of 
syphilitic aortitis with aortic regurgitation and coronary ostial narrowing. The patient was given a full course of penicillin treatment for syphilis without any change in her symptoms.

Surgical repair of the aortic valve defect together with coronary ostial endarterectomy was recommended.

Preliminary angiography was not performed.

\section{A}

B
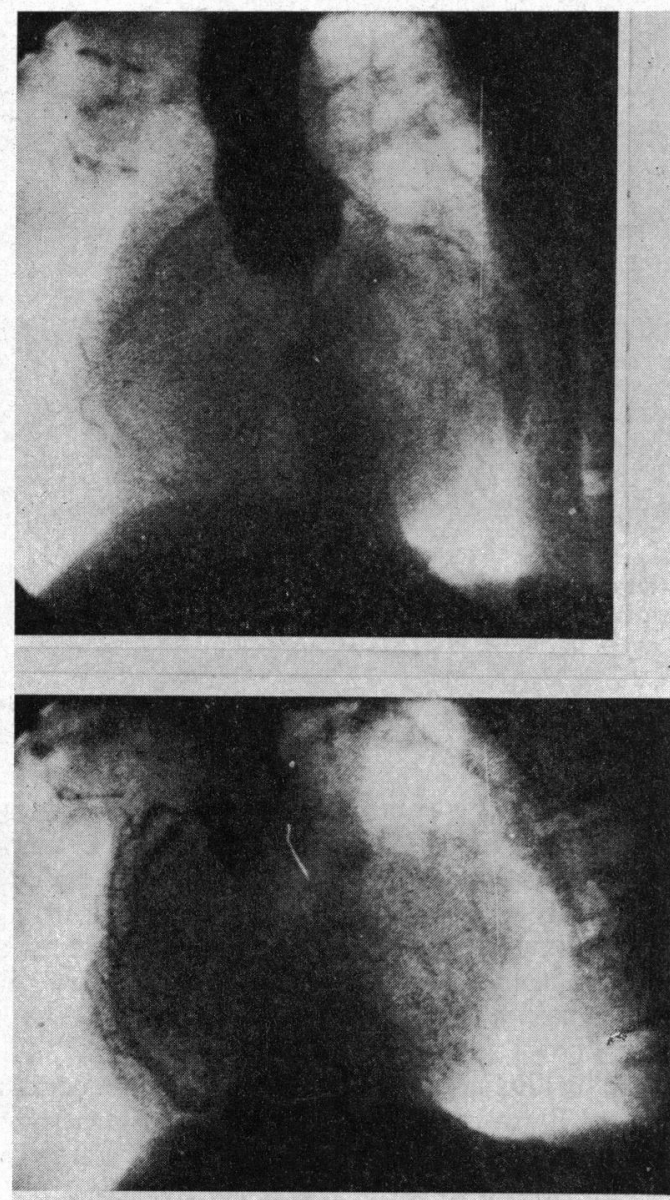

C

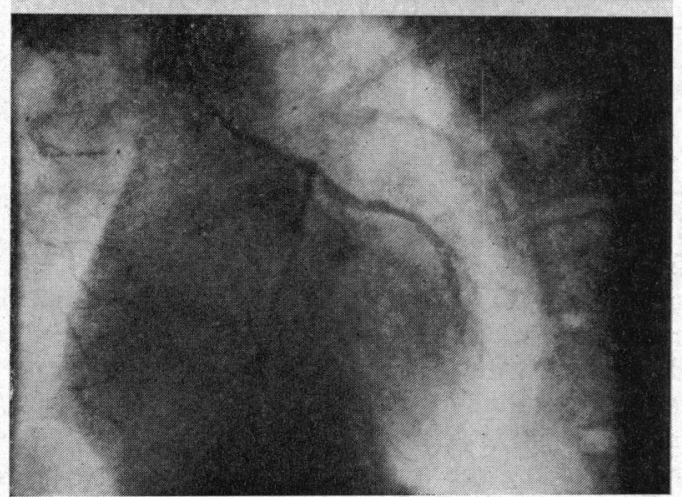

Operation was performed in September 1962, using cardiopulmonary bypass with profound hypothermia, the myocardium being protected by surrounding the heart with ice sludge. The root of the ascending aorta was exposed by means of a median sternotomy and, after cardiopulmonary bypass was commenced, a transverse aortotomy was performed. The intima of the aorta was thick and puckered with much narrowing of both coronary ostia, as a result of syphilitic aortitis. The aortic cusps appeared shortened and the left coronary cusp was prolapsed.

Both coronary ostia were cleared by means of endarterectomy, revealing normal coronary arteries. The coronary arteries were intermittently perfused with cold, oxygenated blood. The aortic regurgitation was corrected by lengthening the left coronary cusp with a Bahnson cusp, which was sutured in place with interrupted 4-0 silk sutures. The aortotomy was closed and re-warming was begun. Only slight aortic regurgitation appeared to be present after removal of the aortic clamp. After defibrillation the heart took over with a good beat.

The post-operative course was uneventful. After the operation the patient was asymptomatic. A loud (grade 3/6) aortic systolic murmur was present but no diastolic murmur. The blood pressure was $190 / 100 \mathrm{~mm} . \mathrm{Hg}$. Fourteen months later she was still asymptomatic, a loud (grade 4/6) aortic systolic murmur and a trivial early diastolic murmur were audible. The blood pressure was 240/105 mm.Hg. Post-operative angiographic studies were not performed.

FIG. 4.-(A) The post-operative aortic angiogram of Case 1 shows persistence of some aortic regurgitation, but now both coronary trunks can be seen arising from the aorta in the normal way.

(B) A single frame from a selective cineangiogram of the right coronary artery shows a considerable diminution in calibre of the vessel compared with 2(B); the complete involution of the atrial collateral channels and absence of collateral filling of the left coronary artery.

(C) A single frame from the selective left coronary cine-angiogram showing that the left coronary ostium is now patent and that both major branches of this vessel fill normally. 


\section{Discussion}

Cardiovascular syphilis has become a rarity in most countries, since the introduction of penicillin treatment has all but eliminated the tertiary manifestations of the disease. Among the less advanced sections of our population, cardiovascular syphilis is by no means uncommon. In this hospital it accounts for approximately 0.6 per cent of all cases of cardiovascular disease: 0.2 per cent among the Whites and 1-2 per cent in the non-Whites (Schrire, 1964).

We suspect syphilis as a cause of angina pectoris in the younger age-group, especially if other evidence of syphilitic aortitis is present. Disproportionate angina pectoris in the presence of aortic regurgitation as in our Case 2 suggests syphilis. Positive serological tests for syphilis are often useful in diagnosis but also occur quite frequently as an incidental finding in patients with coronary atheroma.

Coronary angiography is the only certain way of establishing that the obstruction is localized to the coronary ostium and that the rest of the coronary vascular tree is normal, serving to differentiate this condition from the much more common atheromatous obstructions that tend to be multiple and slightly more distally situated in the main coronary trunks. Aortic angiography may also be indicated to assess the degree of aortic regurgitation.

Angina pectoris due to granulomatous syphilitic ostial obstruction may improve following a course of penicillin therapy, but this did not occur in our cases, making surgical intervention imperative. Because of the relative accessibility of the coronary ostia and because the rest of the coronary vascular bed is generally normal the post-operative results are likely to be extremely gratifying, unlike the results of endarterectomy in most cases of occlusion due to coronary atheroma.

\section{SUMMARY}

Two cases of syphilitic coronary ostial obstruction with severe angina pectoris are reported. In one of these the site of the ostial obstruction and the normality of the rest of the coronary arterial tree were demonstrated before operation by cine-angiography. Successful treatment by endarterectomy of the coronary ostia with complete relief of symptoms in both cases is reported. Angiographic confirmation of the successful result was obtained in one case.

The incidence of syphilitic aortitis, its diagnosis, and the indications for surgical treatment are briefly discussed.

\section{REFERENCES}

Blondeau, P., and Dubost, C. L. (1962). Cure chirurgicale sous hypothermie profonde de la coronarite ostiale syphilitique. A propos de 2 cas opérés avec succès. Ann. Chir. thorac. cardiovasc., 1, 802.

Connolly, J. E., Eldridge, F. L., Calvin, J. W., and Stemmer, E. A. (1964). Proximal coronary-artery obstruction. Its etiology and treatment by transaortic endarterectomy. New Engl. J. Med., 271, 213.

Michaud, P., Froment, R., Pont, M., Viard, H., Termet, H., and Chadenson, O. (1963). Un deuxième cas d'angor syphilitique traité par désobstruction ostiale bilatérale. Lyon chir., 59,575 .

Scharfman, W. B., Wallach, J. B., and Angrist, A. (1950). Myocardial infarction due to syphilitic coronary ostial stenosis. Amer. Heart J., 40, 603.

Schrire, V. (1964). The racial incidence of the less common forms of heart disease at Groote Schuur Hospital, Cape Town, 1952-1961. S. Afr. med.J., 38, 598. 